Recherches en didactique des langues et des cultures

Les cahiers de l'Acedle

$15-2 \mid 2018$

Quelles médiations en didactique des langues et des cultures?

\title{
L'enseignant comme médiateur interculturel en classe de français langue étrangère en Arabie Saoudite
}

\section{Ahmad Helaiss}

\section{OpenEdition}

\section{Journals}

Édition électronique

URL : http://journals.openedition.org/rdlc/3013

DOI : $10.4000 /$ rdlc.3013

ISSN : 1958-5772

Éditeur

ACEDLE

Référence électronique

Ahmad Helaiss, «L'enseignant comme médiateur interculturel en classe de français langue étrangère en Arabie Saoudite », Recherches en didactique des langues et des cultures [En ligne], 15-2 | 2018, mis en ligne le 02 juin 2018, consulté le 30 avril 2019. URL : http://journals.openedition.org/rdlc/3013 ; DOI : $10.4000 /$ rdlc.3013

Ce document a été généré automatiquement le 30 avril 2019

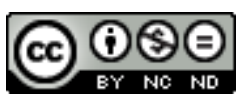

Recherches en didactique des langues et des cultures is licensed under a Creative Commons AttributionNonCommercial-NoDerivatives 4.0 International License 


\title{
L'enseignant comme médiateur interculturel en classe de français langue étrangère en Arabie Saoudite
}

\author{
Ahmad Helaiss
}

\section{Introduction}

1 Les bouleversements qu'engendrent les nouveaux moyens de communication ont enchevêtré les visions de monde et ont redoublé les occasions de malentendus et d'incompréhensions entre les peuples. L'enseignement/apprentissage d'une langue étrangère dépasse largement le fait de parler et d'écrire correctement en cette langue. Il est plus que jamais nécessaire de pouvoir répondre aux enjeux qu'impose le monde d'aujourd'hui. L'enseignant de langue joue un rôle crucial. Sa mission ne se limite pas au fait de transmettre des savoirs quelconques : linguistiques ou culturels. Il doit désormais assumer d'autres responsabilités. Byram et al. (2002:15) font remarquer que parmi les fonctions importantes que l'enseignant de langue doit assumer figure celle qui consiste à «faire naître des capacités, des points de vue et une prise de conscience tout autant que la simple transmission d'un savoir sur une culture ou un pays donné. » La découverte de la culture du pays de la langue étrangère permet de penser profondément à sa propre culture et à son identité par rapport à celles des autres (Barthélemy, $2007: 139-140)$. Tout cela s'inscrit véritablement dans une perspective de médiation interculturelle. Car l'enseignant est vu par l'apprenant comme «le relais nécessaire, le médiateur privilégié vers cette autre culture, celle dont il enseigne la langue et vers la sienne propre, celle dont l'enseignant lui-même est issu » (Gohard-Radenkovic, 2004: 11). C'est ainsi que l'enseignant est considéré comme le médiateur interculturel par excellence.

2 La notion de médiation occupe une grande importance en didactique des langues et cultures. Elle suscite de plus en plus l'intérêt des chercheurs. Elle ne devrait pas être abordée ici sans une brève clarification. Le terme «médiation » vient du latin mediare qui veut dire être au milieu. L'usage du terme «médiation » a été introduit aux États-Unis en 
1970 dans le champ de la jurisprudence et du droit (Gautheron-Boutchatsky et al 2003 : 181). C'est à partir de là qu'il s'est répandu dans la plupart des pays européens et dans le Commonwealth. Lévy et Zarate (2003:188) soulignent que le terme a été emprunté au domaine diplomatique dans le sens de "gérer l'équilibre des relations engagées sur des principes de souveraineté ou d'influence nationales souvent concurrents mais que la médiation va tenter de rendre complémentaires et interactifs ». Elles affirment dans le même ordre d'idée que ce terme a été déjà utilisé « dans la société civile pour structurer des modalités défaillantes de la communication publique et privée » (Ibid. 186).

Par ailleurs, l'acte d'enseigner est, en réalité, une forme de médiation. Cuq et Gruca (2005: 123) définissent l'enseignement comme " une tentative de médiation organisée entre l'objet d'apprentissage et l'apprenant ». En didactique des langues et cultures, la classe de langue et culture étrangères constitue le lieu idéal où l'enseignant, étant l'épine dorsale du système d'enseignement, « devient ]... [ un médiateur entre deux - ou plusieurs - cultures. La manière dont l'enseignement se passe en classe dépend largement de ce que les différents enseignants jugent approprié» (Aleksandrowicz-Pedich et al. 2005 : 9). La notion de médiation interculturelle se définit comme l'ensemble des «processus visant la (re)mise en communication de personnes ayant différentes visions des choses " (Stalder et Tonti, $2014: 2$ ). Cela étant dit, comment l'enseignant de langue peut-il devenir un enseignant-médiateur compétent alors qu'il se trouve face à une dimension aussi vaste que la médiation interculturelle? Nous allons tenter dans les lignes qui suivent d'apporter notre contribution aux travaux déjà effectués dans ce domaine important.

Pour la réalisation de cette étude, nous nous sommes appuyé sur une enquête de terrain qualitative à base d'entretiens semi-directifs auprès d'enseignants du département de français à la faculté des langues et de traduction durant le deuxième semestre de l'année 2015. La méthodologie adoptée visait à rassembler l'ensemble des opinions, des positions, des attitudes et des expériences propres à faire apparaître les manques théoriques et méthodologiques de l'approche interculturelle chez les enseignants de français à l'Université du Roi Saoud en Arabie Saoudite. Nous avons choisi de restreindre les personnes sondées uniquement aux enseignants en raison de leur rôle important comme médiateurs. Nous avons donc réalisé sept entretiens avec sept enseignants ayant au moins une vingtaine d'années d'expérience dans les domaines de l'enseignement des langues et de la traduction.

\section{Absence de formation initiale des enseignants de français et de traduction}

5 Les enseignants de langues sont supposés être des passerelles permettant et garantissant la compréhension de l'autre culture. Le discours qu'ils tiennent sur la langue et la culture étrangères est considéré par les apprenants comme une source de vérité traduisant la réalité culturelle de la langue cible au même titre que le manuel. Toutefois, toute la complexité de la tâche de l'enseignant-médiateur réside dans cette problématique. Force est de constater que la formation initiale à la perspective interculturelle chez les enseignants n'est malheureusement pas de mise au sein de la faculté des langues et de traduction. Tous les enseignants sont de formation linguistique ou littéraire. Ce manque flagrant d'une formation à l'interculturel a un impact majeur sur leurs conceptions, leurs opinions et leurs pratiques vis-à-vis de la culture étrangère comme nous allons le voir dans les lignes qui suivent. 
6 Nous avons constaté que les enseignants adoptaient une approche purement « culturaliste ». La culture est abordée en termes de connaissances culturelles de manière factuelle. L'enseignant possède une grille d'éléments culturels prédéfinis à aborder dans deux cours intitulés :

- Lectures dans la culture de la langue cible $2 \mathrm{~h}$ (quatrième semestre).

- Culture comparée $2 \mathrm{~h}$ (cinquième semestre). ${ }^{1}$

7 Ces cours sont centrés uniquement sur un aspect descriptif en se basant sur des connaissances culturelles factuelles sur la France, les Français et la culture française (pratiques quotidiennes des Français, sorties, loisirs, fêtes, différents modes de mariage, gastronomie, lieux et monuments symboliques, etc.). Cette approche dite «culturaliste » bien qu'elle soit nécessaire, n'est pas, à notre avis, suffisante. Dans une perspective interculturelle, elle contribue à renforcer davantage l'ancrage des stéréotypes chez les apprenants. De plus, ayant mené personnellement l'expérience au sein de ce département, nous nous sommes aperçu que ces cours visaient avant tout à améliorer le niveau linguistique des apprenants et se transforment très souvent en cours d'entraînement à la lecture, donc à des fins purement linguistiques.

Dans cette optique, les enseignants de langue doivent être sensibilisés au fait qu'ils ne sont pas tenus de tout savoir sur la culture cible puisqu'ils ne sont pas en mesure de prévoir quel serait l'ensemble des connaissances culturelles dont les apprenants ont besoin pour bien connaître et comprendre la culture cible. Ils devraient plutôt faire prendre conscience à leurs apprenants qu'il existe des limites quant aux connaissances culturelles et qu'il ne s'agit pas seulement de fournir des connaissances factuelles et des savoirs sur la culture étrangère. La culture constitue une entité dynamique, non immuable et en mutation permanente.

Dans une perspective de médiation interculturelle, les enseignants se doivent d'adopter une démarche interprétative et compréhensive plus qu'explicative ou descriptive. Leur rôle ne s'arrête pas à la simple inculcation des connaissances culturelles sur la communauté de la langue cible. Cette méthode « culturaliste » est contreproductive et ne déboucherait que sur des conséquences non souhaitées.

\section{Le piège de l'ethnocentrisme : questionner les représentations}

10 Les représentations et les stéréotypes sont souvent considérés comme des écueils face à une meilleure compréhension lorsque nous entrons en contact avec l'Autre ou dans la perception de celui-ci. Le problème auquel les enseignants doivent faire attention en classe, c'est le discours qu'ils tiennent sur la culture étrangère. Ce discours peut être positif ou négatif. Naturellement, les enseignants tiennent un discours très positif et angélique vis-à-vis de la langue et de la culture qu'ils enseignent. Ils veulent communiquer leur enthousiasme à leurs apprenants. Mais cela est susceptible de donner une image trompeuse et totalement différente de la réalité. C'est pourquoi nous avons cherché à savoir comment les enseignants réagissent face aux représentations et stéréotypes de leurs apprenants.

11 Dans les réponses fournies par les enseignants, nous avons constaté que les enseignants étaient divisés en deux groupes. Le premier groupe n'essaye jamais d'intervenir ni d'influencer le discours de leurs apprenants. Ils se contentent de la simple transmission 
des connaissances culturelles telles qu'elles sont. Le rôle qu'ils estiment devoir jouer est le simple fait de transmettre les connaissances culturelles en toute "objectivité » sans pour autant être amenés à intervenir. Le témoignage de cet enseignant est révélateur de cette problématique: "mon rôle consiste au fait de transmettre les connaissances culturelles aux apprenants et c'est à eux d'apprécier les points négatifs ou positifs de la culture française même s'ils leur semblent étranges ou choquants ou pas. »

Nous pouvons constater qu'il existe une sorte de sous-estimation de l'impact que peuvent entrainer les représentions que se font les apprenants vis-à-vis de la culture étrangère. Le fait de ne pas intervenir pour questionner les stéréotypes et les préjugés qui ne sont pas inévitables et qui sont enracinés dans l'inconscient collectif ne fait que les renforcer davantage. Dans cette optique, il importe de rappeler également que notre devoir en tant qu'enseignant de langue et de traduction est de faire prendre conscience à l'apprenant de ces problèmes inhérents à la médiation interculturelle. L'un des articles de foi incontestés des professeurs de langue est: "la compréhension d'une culture et d'une autre civilisation devrait contribuer à réduire les préjugés et promouvoir la tolérance » (Byram, 1992 : 34).

Le deuxième groupe (plus que la moitié) préfère intervenir et expliquer. Mais force est de constater qu'ils se réfèrent à leurs expériences personnelles et à leur vécu en France (voyages d'études et voyages touristiques), etc. Ils essayaient de confronter la culture étrangère et la culture locale mais de manière plus ou moins inconsciente, loin d'être méthodique et non sous-tendue par une approche interculturelle. L'enseignant ci-après, par exemple, nous montre comment il procède en classe pour expliquer à ses apprenants les questions relatives à l'interculturel. Il se réfère à ses propres expériences, sachant qu'il a vécu en France dans les années 80 :

c'est par l'explication euh on n'a pas d'autres moyens pour ça mais en est en train de prêcher l'ouverture d'esprit et de de d'expliquer certains éléments à partir de nos propres expériences et les problèmes auxquels nous nous sommes heurté pendant notre séjour en France.

14 C'est vrai que les expériences menées par les enseignants leur ont permis de mieux connaître et appréhender la culture française en vue de la transmettre. Mais, leurs connaissances sur la culture française sont souvent imprégnées de leur propre vision du monde. Ils risquent ainsi de tomber dans le piège de l'ethnocentrisme. Cet enseignant nous a fait aussi part de sa façon d'intervenir auprès de ses apprenants : «je leur explique surtout la différence / et la manière dont il faut voir les choses / les problèmes / / comment il faut agir par exemple quand on est en France euh quand on veut rencontrer quelqu'un parler à quelqu'un si on a un problème etc. ». Nous pouvons remarquer dans le témoignage ci-dessus que l'enseignant n'invite pas ses apprenants à réfléchir et à questionner leurs propres représentations vis-à-vis de l'autre mais leur dicte la façon dont il faut agir, interagir et voir les choses.

Cette méthode contredit les principes de l'approche interculturelle et contribue immanquablement à renforcer davantage l'ancrage des stéréotypes chez les apprenants. Cette méthode est « interculturellement incorrecte» (Zarate, 1986:29). Celle-ci affirme que "ces jugements à l'emporte-pièce, si fréquents [...], sont autant de lampes rouges qui signalent l'erreur de méthode. L'abus consiste à transformer une expérience individuelle en vérité générale "(ibid.). Face à ces questions sensibles, l'enseignant doit aussi être très attentif en décryptant ses expériences personnelles en classe de langue parce que la parole de l'enseignant est perçue souvent chez les apprenants comme un reflet exact de la réalité. 
L'expérience d'un contact avec la culture étrangère enseignée «ne peut être validée que si l'enseignant sait reconnaître et éviter les pièges de l'ethnocentrisme » (ibid.).

En outre, les enseignants de langue sont toujours soumis aux regards de leurs apprenants et sont considérés comme les référents quant à la transmission de la langue et de la culture cible. Ils sont "bel et bien, qu'ils le veuillent ou non, en situation de représentation " (Barthélémy, 2007: 127). Leur domaine d'intervention comme médiateurs porte essentiellement sur les perceptions que se font leurs apprenants vis-à-vis de la culture dont ils apprennent la langue. Car la médiation «interculturelle» est un concept impliquant une confrontation des représentations que véhiculent des individus appartenant à des cultures différentes. Gautheron-Boutchatsky et al (2003 : 181) expliquent ce rapport entre représentations et médiation en ces termes :

Les représentations culturelles sont en tout état de cause des notions qui impliquent une médiation. Le sens que l'on attribue aux objets, aux choses matérielles, est construit à partir de systèmes de représentations qui prennent forme dans des pratiques culturelles, symboliques. La prise de conscience de ces schèmes de représentation facilite la compréhension, la reconnaissance de l'autre.

Rappelons de surcroît que les enseignants sont avant tout des êtres humains. Ils peuvent donc véhiculer consciemment et inconsciemment des stéréotypes sur la langue et la culture à enseigner, que ce soit dans le but de susciter l'envie et l'intérêt chez leurs apprenants ou bien parce qu'ils sont eux-mêmes victimes des images stéréotypées qu'ils ont intériorisées par divers moyens. Dans cette optique, comme le fait remarquer Cuq (2003), l'enseignant doit adopter une attitude relativiste et être constamment conscient du poids de l'ethnocentrisme sur ses schémas de pensée, sur ses interactions exolingues et sur ses enseignements. L'auteur insiste également sur le fait que cette attitude doit être encouragée chez l'apprenant pour lui permettre d'appréhender correctement les habitus du groupe social dont il tente de s'approprier la langue. Il propose de recourir à une réciprocité des perspectives et à l'application de la méthode de l'observation participante qui sont probablement les meilleurs moyens permettant d'éviter l'ethnocentrisme. C'est ainsi que l'enseignant doit faire " un travail systématique sur ses propres représentations de la culture cible, accepter qu'il existe chez les élèves des différences individuelles quant à l'acceptation de nouveaux systèmes de valeurs, et que sa propre "vérité" n'est bien sûr pas la seule " (Eisl, $2006: 11)$

Cette démarche est d'autant plus importante que l'enseignant se trouve parfois désarmé face à des réactions de rejet et d'indifférence de la part de ses apprenants. C'est plus particulièrement vrai lorsque ces derniers n'arrivent pas à accepter et à comprendre les éléments culturels qui leur semblent étranges car contraires à leurs valeurs et croyances fondamentales. Les apprenants disposent très souvent de savoirs et de certitudes qui sont profondément enracinés dans leurs esprits et n'ayant jamais fait l'objet de remise en cause. L'enseignant se doit d'insister sur le fait qu'il existe une grande divergence de visions du monde aussi bien entre individus appartenant à des cultures différentes qu'entre individus de la même communauté culturelle. S'ajoute à cela le fait de faire prendre conscience aux apprenants qu'il existe d'autres façons de pensée qui peuvent leur apparaître anormaux afin d'éviter toute forme d'ethnocentrisme. 


\section{L'appartenance culturelle des enseignants}

19 L'appartenance culturelle des enseignants a un impact non négligeable sur la mission de l'enseignant en tant que médiateur interculturel. C'est d'autant plus délicat lorsque la culture cible à enseigner relève d'une sphère culturelle différente ou éloignée. C'est le cas de nos apprenants saoudiens de français langue étrangère. Nous avons posé aux enseignants la question suivante: est-ce que l'enseignant natif est mieux placé pour transmettre sa propre culture en classe de langue? Les réponses des enseignants à cette question nous ont conduit à aborder cette problématique en distinguant deux situations qui sont susceptibles d'induire des risques nuisant à la qualité de l'enseignement interculturel.

La première est relative au discours des enseignants issus de la communauté culturelle des apprenants (enseignants arabes). Il faut souligner que les enseignants dans le département de français sont majoritairement de nationalités différentes: syrienne, soudanaise, jordanienne, égyptienne, tunisienne. Bien qu'ils appartiennent tous à la même sphère culturelle (culture arabo-musulmane), néanmoins, il existe des différences notables entre leurs propres cultures et la culture saoudienne et ce sur plusieurs plans. La vision du monde est très différente sous plusieurs aspects : religieux (pratiques, école de jurisprudence différente, etc.) sociaux (coutumes, rapports homme/femme, etc.). Cela est susceptible de compliquer davantage la tâche de ces enseignants. Ces derniers n'appartiennent pas tous exactement ni à la culture de leurs apprenants ni à la culture enseignée. Pourtant, nous avons constaté qu'ils jouaient le rôle de transmetteurs des connaissances qu'ils ont acquises par divers moyens notamment à travers leurs propres expériences de voyages et de séjours en France.

La deuxième situation concerne l'enseignant français. Nous avons constaté que tous les enseignants sans exception sont unanimes sur le fait que l'enseignant natif n'est pas le mieux placé pour enseigner sa propre culture. Certains affirment que le natif n'est pas meilleur enseignant de sa culture que l'enseignant non natif s'il n'est pas suffisamment formé et qualifié. D'après eux, le seul apport de l'enseignant natif réside dans l'enseignement de la langue parce qu'il peut transmettre la bonne prononciation et l'accent standard en français. D'autres enseignants corroborent cette remarque en nous signalant que suite à des expériences avec des enseignants Français ayant enseigné au département de français en Arabie Saoudite, il y a eu beaucoup de problèmes et malentendus avec les apprenants saoudiens. En effet, ils n'étaient pas suffisamment formés à la culture saoudienne, comme le montre le témoignage de cet enseignant :

je parle de notre expérience dans ce département à partir de ça nous avons eu plusieurs natifs euh qui ont enseigné le français dans ce département / on a eu des étudiants qui ont eu beaucoup de problèmes avec ces natifs parce que souvent il sont des jeunes ce sont des jeunes qui ne sont pas formés dans ce bain interculturel donc ils ne sont pas tout à fait conscients de problèmes interculturels ils (les enseignants) ont euh ils viennent ici avec leurs stéréotypes avec leur préjugés sur la culture arabo-musulmane en plus de cela ils viennent aussi avec un bagage ou bien euh ils pensent être supérieurs aux autres peut-être avec un complexe de supériorité / ils pensent qu'ils détiennent la vérité et vont transmettre cette vérité donc / l'enseignement qu'ils qu'ils qu'ils font se fait se fait quelquefois au détriment de la culture arabo-musulmane d'où une source de malentendu parmi les étudiants d'où / 
la création de problèmes quelquefois plus ou moins forts entre eux et ces étudiants parce que leurs comportements ne respectent pas tout à fait les consignes de la culture arabo-musulmane et ça a posé et a créé // au lieu d'enseigner la culture française eux-mêmes ils deviennent des mauvais transmetteurs de leur culture et au lieu d'influencer les autres de les attirer vers leur culture française ils étaient en train en fait de donner une mauvaise image de la culture française ou occidentale. son statut privilégié. Il est considéré aux yeux des apprenants comme porteur de messages authentiques et donc plus compétent sur les deux plans:linguistique et culturel. Derivry-Plard (2008: 148) constate que le mécanisme de représentations que se forgent les apprenants sur l'enseignant natif s'opère de la manière suivante : puisque ce dernier est du pays de la langue enseignée, il représente la culture du pays et en possède la connaissance. On passe, d'après lui, sans bien réfléchir de l'étape «il connaît la culture » et/ou «il sait enseigner la culture » à l'étape «il a la culture» et par conséquence «il est la culture». Ainsi, les apprenants peuvent le prendre pour un prototype de tout locuteur français et tombent dans le piège de la généralisation. L'enseignant originaire du pays de la langue à apprendre, faute d'une formation à l'interculturel, ne peut pas éviter d'être affecté par sa culture maternelle et donc par «l'ethnocentrisme ». Il est incapable d'être :

une autorité sur l'ensemble des cultures existantes dans son pays, ou de trancher sur ce qui est « correct » ou « incorrect », comme il peut le faire, en principe, pour la langue. En outre, la compétence interculturelle n'est qu'en partie une question de connaissance; en l'occurrence, ce sont les autres dimensions (savoir être, savoir apprendre/faire, savoir comprendre et savoir s'engager) qui doivent être privilégiées dans les processus d'enseignement et d'apprentissage (Byram et al., $2002: 19)$.

La question ne doit pas donc se limiter au fait d'être un locuteur natif, national ou nonnational pour enseigner la culture cible de manière optimale. Il s'agit plutôt de la capacité et de l'aptitude de l'enseignant, quelle que soit son origine, à analyser le système de culture de la langue cible. Il est nécessaire de prendre conscience des phénomènes résultant de la confrontation avec la langue et la culture source.

\section{L'approche comparative}

Les enseignants du département de français ont toujours recours à l'approche comparative dans la confrontation de la culture étrangère et de la culture maternelle de leurs apprenants. Ils demandent aux apprenants de choisir un élément culturel français, à aborder en classe sous la forme d'un exposé, et de le comparer avec un élément culturel saoudien. S'appuyer sur une telle démarche n'est pas sans risque ni sans danger. Abdallah-Pretceille (1996: 99) a mis en garde, à plusieurs reprises, contre toute approche comparative et analogique. Selon elle, "quelle que soit la séduction du comparatisme en pédagogie, il n'en comporte pas moins, sur le plan théorique, un certain nombre de dangers ». La même auteure va même jusqu'à prévenir des inconvénients de l'application de la comparaison comme angle d'analyse des cultures car elle débouche fatalement sur une classification qui échappe difficilement à la hiérarchisation. La comparaison est donc 
d'après elle "méthodologiquement douteuse, éthiquement et théoriquement spécieuse » (ibid :102). Les effets négatifs que peut induire cette approche comparative sont les suivants :

- Prétendre l'universalité de sa propre culture par rapport à l'autre culture. vouloir retrouver dans chaque culture les mêmes éléments mais sous des formes différentes ou des degrés de maturité différentes implique la croyance en l'existence d'un schéma culturel universel à partir duquel s'ordonneraient toutes les cultures. Or, on le sait, chacun ramène l'universel à soi-même (Abdallah Pretceille, 1983 :41).

- La hiérarchisation des valeurs culturelles. L'approche comparative peut «amener à une hiérarchie consciente ou inconsciente d'ordre de valeur culturelle» (Windmüller, $2011: 40$ ).

- Le renforcement de stéréotypes et de préjugés. «La comparaison des deux cultures en présence ] ...[ risque de renforcer les images stéréotypées et d'attiser la résistance et le rejet " (Méziani, 2009: 270).

À partir de là, il importe de préciser que l'approche interculturelle n'est pas une comparaison entre deux cultures basée sur l'appropriation des éléments culturels de différences ou de similitudes que nous pouvons repérer facilement dans des faits, des pratiques, etc. Il faudrait adopter plutôt une approche de réflexion, dans laquelle on attire l'attention des apprenants «sur leur propre histoire et leur propre culture, ainsi que sur celles de la culture cible, afin d'expliquer et de mettre en regard les différences » (Skopinskaja, $2005: 62$ ).

La mission essentielle de l'enseignant-médiateur est d'adopter "une démarche, une pédagogie interactionniste et constructiviste qui amène l'apprenant à effectuer un apprentissage qui se dirige vers l'Autre, mais avant tout vers lui-même, avant de trouver sa raison d'être en situation de contact entre les personnes de cultures différentes " (Windmüller, 2011: 20). L'enseignant-médiateur est amené à interpréter la matière enseignée avec et pour les apprenants, développer leurs capacités et faire naitre des aptitudes interculturelles leur permettant d'appréhender aussi bien le fonctionnement de l'univers culturel d'autrui que le leur. Il s'agit enfin de les préparer à toute rencontre potentielle avec des personnes appartenant à d'autres cultures et d'en tirer profit. L'enseignant dans ce contexte doit « apprendre ou savoir comment apprendre à limiter les risques, à anticiper et à gérer ces aléas d'une communication qui ne peut être qu'interculturelle » (Gohard-Radenkovic, $2004: 10)$.

\section{Se confronter à l'universalité du manuel}

Le manuel est un moyen très important et très pratique dont l'enseignant et l'apprenant ont besoin pour faciliter l'enseignement/apprentissage surtout en milieu exolingue. Il sert de support de référence et de médium entre l'apprenant d'une part et la langue et la culture étrangères d'autre part. Connexions ${ }^{2}$ est le manuel utilisé au département de français depuis déjà 13 ans. Lorsque nous avons interrogé les enseignants sur l'utilité de ce manuel, certains ont répondu qu'il était daté maintenant et qu'il n'accordait pas d'importance à l'aspect culturel, comme le note cet enseignant :

/ / / euh bien sûr parce que je pense que les manuels utilisés fin les manuels qui ont été utilisés qui sont actuellement utilisés n'accordent pas assez d'importance à cet cet aspect culturel j'ai : j'ai essayé de par moi-même disons de compléter le contenu de ces manuels d'apporter un certain : euh comment dit un certain ajout culturel à mon enseignement et ceci dans le 
cadre de bien sûr de de faire acquérir l'aspect culturel et de sensibiliser mon public sur l'importance de cet aspect. premier outil d'apprentissage et la première fenêtre qui donne sur la culture étrangère. Mais en effectuant une analyse de ce manuel, nous avons constaté qu'il est de type " généraliste ». Il fait partie des manuels dits "universalistes». Ils sont destinés à un large public que ce soit en France ou à l'étranger. Les concepteurs prétendent tenir un discours interculturaliste alors qu'en réalité ce n'est qu'un discours culturaliste qui y est adopté. Dans son analyse de plusieurs manuels à vocation « universaliste » (Dervin, 2011) affirme que les concepteurs de manuels des langues étrangères prétendent s'être penchés sur l'interculturalité alors que leurs manuels ne soutiennent pas la vraie rencontre, le vrai divers et les diverses diversités de soi. Il souligne dans le même ordre d'idée que malgré la présence des altérités dites "périphériques", le soi et l'autre sont souvent présentés par des images et représentations figées. De plus, ces manuels tendent à " préparer les apprenants à un ensemble de situations de communication parfois éloignées de celles auxquelles les apprenants seront confrontés en milieu authentique » (Windmüller, 2007 : 117).

Il est donc fortement recommandé que les manuels soient contextualisés, c'est-à-dire conçus pour un public donné. Pour ce faire, il est indispensable de réunir les éditeurs des manuels de français et des enseignants pour concevoir un manuel contextualisé qui repose sur une réflexion didactique et une démarche méthodologique tenant compte de l'approche interculturelle. Il faudrait insister également sur le fait que la conception d'une méthode contextualisée doit être basée sur des études empiriques menées sur le terrain: enquêtes auprès des apprenants, des enseignants et des responsables éducatifs ainsi que par le biais d'observations directes en classe de langue. Cette étape permettrait d'avoir une vue d'ensemble sur la réalité de la situation et de prendre conscience des centres d'intérêts des apprenants ainsi que de leurs besoins en termes d'enseignement/ apprentissage d'une langue et d'une culture étrangères.

Mais faute d'une telle démarche qui semble du moins jusqu'à présent, non envisageable par le département, l'enseignant devrait être amené à se confronter à l'universalité de ce manuel. Dans ce contexte, une intervention compensatoire de la part de l'enseignant en tant que médiateur serait nécessaire pour combler l'insuffisance ou la faiblesse de la méthode. Pour ce faire, il se doit de trouver un compromis didactique entre le manuel imposé par l'institution et la particularité du contexte d'enseignement/apprentissage. Et ce, pour que le contenu soit approprié à son public. Le contenu du manuel, qu'il soit contextualisé ou non, ne fait pas l'enseignement. Il dépend largement de la manière dont l'enseignant l'utilise en classe et de ce que ce dernier juge convenable et approprié. Le manuel ou bien l'ensemble pédagogique «n'est qu'un outil mis à la disposition de l'enseignant et des enseignés pour les aider, dans le contexte qui est le leur, à (faire) acquérir la langue 
étrangère » (Besse, 1985 : 15). L'important est donc d'adapter le manuel existant pour qu'il soit approprié au contexte d'enseignement et aux besoins des apprenants.

L'enseignant ne doit pas utiliser le manuel de façon rigide en suivant méticuleusement et à la lettre le contenu qui y est présenté. Il est plutôt invité à avoir de la souplesse et à sélectionner le contenu approprié qui répond le mieux aux besoins des apprenants et aux objectifs poursuivis. Il est également amené à introduire des modifications aux exercices, aux thèmes et aux activités que le manuel propose. De surcroît, compte tenu de l'évolution rapide des sociétés modernes, l'enseignant doit toujours veiller à intégrer des documents plus proches des centres d'intérêts des apprenants. Rappelons d'ailleurs qu'adapter le manuel au contexte des apprenants ne signifie pas le censurer. L'enseignant doit éviter la censure car même si cela part des meilleures intentions, la censure est susceptible de priver «les apprenants de l'aptitude à se défendre contre des concepts ou des affirmations inacceptables du point de vue culturel » (Skopinskaja, $2005: 62$ ).

\section{Conclusion}

33 Il est fort probable que les enseignants peuvent se trouver à un moment donné de leur enseignement dans un état d'insécurité et de malaise, en ayant le sentiment d'être désarmés face aux réactions de leurs apprenants sur les aspects interculturels. En effet, la médiation interculturelle, selon les propos de Barthélémy (2007:140) «n'est pas innée et se construit, "se fabrique », donc s'enseigne, ce qui stipule une formation des enseignants adéquate, qui n'est toujours pas de mise aujourd'hui. » Pour mettre en place une telle formation en faveur des enseignants, il nous semble indispensable que les enseignants se familiarisent avec les idées de base de l'anthropologie culturelle, les théories de l'apprentissage de la culture et de la communication interculturelle. Il est ainsi envisageable d'organiser une formation animée par des professionnels et spécialistes en la matière en faveur des enseignants de tous les départements de la faculté des langues et de traduction. Cette formation doit se fixer comme objectif :

L'acquisition des démarches et d'outils empruntés à des disciplines connexes telles que les sciences sociales ou sciences de la culture afin de mettre en place une lecture objectivée des expressions visibles et invisibles d'une société à travers le décodage des pratiques et comportements socioculturels (Gohard-Radenkovic, $2004: 141-142$ ).

Il faudrait tenir compte des différents paramètres interculturels que nous avons cités précédemment comme: adopter une démarche réflexive plutôt que comparative et descriptive, prévoir un nouveau manuel qui prend en compte aussi bien la culture enseignée que la culture des apprenants, se méfier de toute approche culturaliste, prendre en compte leurs propres représentations et celles de leurs apprenants pour éviter de tomber dans le piège de l'ethnocentrisme.

Il est nécessaire également de mener un travail rigoureux sur les représentations initiales des apprenants pour les exploiter au fur et à mesure de leur progression dans l'apprentissage de la langue et la culture françaises. L'enseignent doit être apte « ̀̀ conduire des représentations premières à des représentations travaillées, passées par l'observation, l'analyse, l'objectivation et la prise de conscience » (Beacco, 1995 :12). Cela permettra aux enseignants de gérer la confrontation potentielle de visions et d'être capables d'aider les apprenants à déchiffrer les documents fortement codés. L'enseignant-médiateur doit être 
en mesure de développer l'aptitude à mieux comprendre, expliquer et interpréter les phénomènes résultant de tout contact avec la culture de la langue cible.

Baser l'enseignement sur une telle perspective constitue une vraie passerelle qui devrait forcément aboutir à un rapprochement et une intercompréhension entre individus appartenant à des cultures différentes. Et ce, pour remédier à "l'incommunicabilité » dont parle Claude-Lévi Strauss ${ }^{3}$. Il est alors question de prendre en considération tous ces paramètres dans la classe de langue pour donner un nouvel élan à l'enseignement de langue et de culture étrangères. C'est ainsi que l'enseignant mérite vraiment d'être considéré comme le médiateur interculturel par excellence.

\section{BIBLIOGRAPHIE}

Abdallah-Pretceille M. (1983). « La perception de l'autre. Points d'appui de l'approche interculturelle ». In Le Français dans le monde, n 181, Hachette/Larousse.

Abdallah-Pretceille M. (1996). Vers une pédagogie interculturelle, 3ème édition, Paris : Anthropos.

Aleksandrowicz-Pedich L. et al. (2005). « Opinions des enseignants d'anglais et de français sur la compétence en communication interculturelle dans l'enseignement des langues ». In I. Lázár (Ed). Intégrer la compétence en communication interculturelle dans la formation des enseignants. Kapfenberg : Conseil de l'Europe, pp. 9 - 44.

Barthelemy F. (2007). Professeur de FLE : historique, enjeux et perspectives. Paris : Hachette.

Besse H. (1985). Méthodes et pratiques des manuels de langue. Paris : Didier-Crédif.

Byram M. (1992). Culture et éducation en langue étrangère. Paris : Hatier/Didier, Collection LAL.

Byram. M. Gribkova. B., \& Starkey. H. (2002). Développer la dimension interculturelle dans l'enseignement des langues. Une introduction pratique à l'usage des enseignants. Strasbourg : Conseil de l'Europe.

Cuq J.-P. \& Gruca I. (2005). Cours de didactique du français langue étrangère et seconde (nouvelle version). Grenoble : PUG.

Cuq. J-P. (2003). Dictionnaire de didactique du français langue étrangère et seconde. Paris : Clé international.

Derivry-Plard M. (2008). « Comment les étudiants se représentent-ils leurs enseignants de langue étrangère ? » In P. Martinez, D. Moore \& V. Spaëth. Plurilinguisme et enseignement : identités en construction. Paris : Riveneuve éditions, pp. 141-152.

Dervin F. (2011). Impostures interculturelles, logiques sociales. Paris : l'Harmattan.

Eisl M. (2006). « La perspective interculturelle en FLE : des principes didactologiques aux activités de classe (enseignement secondaire autrichien). In Travaux de didactique du FLE 54, IEFE Montpellier III. Études de linguistique appliquée 2012/3 ( $\left.n^{\circ} 167\right)$, pp. 261-263.

Gautheron-Boutchatsky, Ch. et al. (2003). « Représentations du concept d'altérité dans la publicité et médiation culturelle ». In G. Zarate A. Gohard-Radenkovic, D. Lussier et H. Penz (2003). 
Médiation culturelle et didactique des langues, Centre européen pour les langues vivantes. Editions du Conseil de l'Europe.

Gohard-Radenkovic A. (2004). Communiquer en langue étrangère : de la compétence culturelle vers des compétences linguistiques. Berne : Peter Lang.

Lévy D. \& Zarate G. (2003). « La médiation dans le champ de la didactique des langues et cultures ». In Le Français dans le monde, recherches et applications. Paris : Clé international.

Meziani A. (2009). «Pour une valorisation de la compétence interculturelle en classe de FLE ». In Synergie Algérie, $\mathrm{n}^{\circ}$ 4, pp. 265-272.

Régine M. \& Yves L. (2004). Connexion 1 : méthode de français. Paris : Edition Didier.

Skopinskaja, L. (2005). « Le rôle de la culture dans les matériels d'enseignement de langues étrangères : une évaluation d'un point de vue interculturel » In Ildikó Lázár, Intégrer la compétence en communication interculturelle dans la formation des enseignants. Centre européen pour les langues vivantes : Editions du Conseil de l'Europe.

Stalder P. \& Toni A. (2014). Introduction : la médiation interculturelle : représentations, mises en œuvre et développement des compétences. Paris : Éditions des archives contemporaines.

Windmüller F. (2007). « Les manifestations de l'éclectisme dans l'enseignement/apprentissage du FLE en Allemagne : liberté d'action ou contrainte pédagogique? » Synergies Chine, $\mathrm{n}^{\circ} 2$.

Windmüller F. (2011). Français langue étrangère (FLE) : l'approche culturelle et interculturelle. Paris : éditions Belin.

Zarate G. (1986). Enseigner une culture étrangère. Paris : Hachette.

Zarate G. (1993). Représentations de l'étranger et didactique des langues. Paris : Didier, Coll. CrédifEssais.

\section{NOTES}

1. Il est à noter que, suite à un changement récent du cursus universitaire au sein de l'Université du Roi Saoud, la faculté des langues et de traduction a réduit le nombre de semestres à 8 semestres (4 ans) au lieu de 10 semestres ( 5 ans). Et ce, pour valider le diplôme universitaire appelé baccalauréat (Licence en France) en langue étrangère et en traduction. Les cours dédiés à la culture et à la civilisation de la langue cible ont été donc affectés par cette décision administrative et ont été réduits à deux cours (2h chacun) par semaine au lieu de trois.

2. Régine Mérieux et Yves Loiseau, 2004, Connexion 1 : méthode de français, Éditions Didier.

3. Dans la préface de son ouvrage Lévi Strauss (1983). Regards éloignés. Paris : Librairie Plon.

\section{RÉSUMÉS}

L'enseignant de langues est plus que jamais amené à assumer sa responsabilité en tant que médiateur interculturel. Face à cette responsabilité, comment l'enseignant peut-il être en mesure de jouer ce rôle aussi bien humaniste que scientifique dans un domaine aussi vaste que la 
médiation interculturelle? Dans cet article, nous allons d'abord mettre l'accent sur quelques cas de figure constatés à travers notre propre expérience comme enseignant au département de français à l'Université du Roi Saoud par le biais d'une enquête de terrain réalisée en 2015 auprès des enseignants. Dans un second temps, nous allons ébaucher quelques directives méthodologiques et recommandations didactiques pour favoriser la prise en compte de l'approche interculturelle dans l'enseignement de français en Arabie Saoudite.

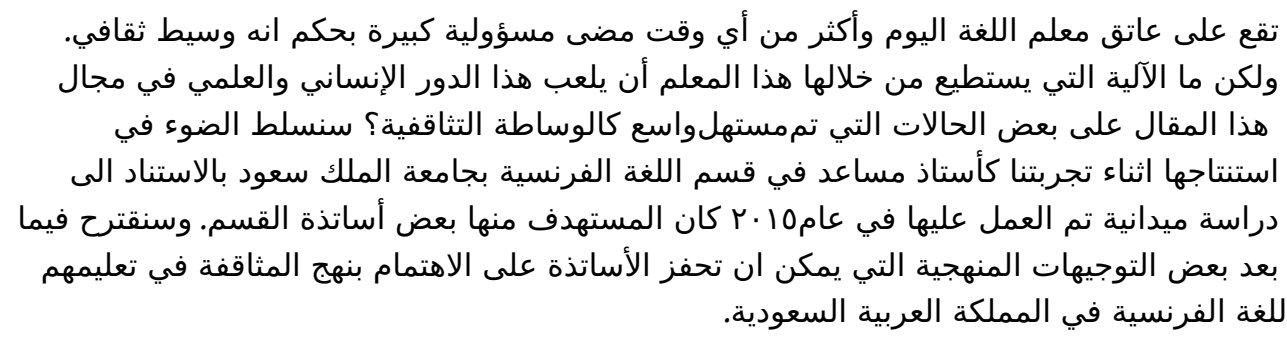

\section{INDEX}

Mots-clés : français langue étrangère, culture, médiation interculturelle, représentations

Keywords : french as a foreign language, culture, intercultural mediation, representations

\section{AUTEUR}

\section{AHMAD HELAISS}

Maître de conférence à l'Université du Roi Saoud à Riyad.

Ahmad Helaiss occupe actuellement le poste de professeur assistant « maître de conférence » à l'Université du Roi Saoud à Riyad. Il est titulaire d'un doctorat en sciences du langage de l'Université de Rouen en 2014. Sa thèse s'intitule : Les dynamiques des représentations sociales dans la mise en cuvre d'une didactique de l'interculturel : analyse de discours d'apprenants saoudiens en situation de mobilité étudiante en France. Ses recherches portent principalement sur la didactique des langues et cultures, la communication interculturelle et la traduction.

Courriel : alholeissy[at]hotmail.com 